\title{
SERVQUAL Model in HEI Monitoring Survey as a Part of Quality Assurance Policy
}

\author{
Mykola Sydorov *[0000-0002-5333-8393], Svitlana Salnikova ${ }^{[0000-0001-6368-9480]}$
}

Taras Shevchenko National University of Kyiv, Kyiv, Ukraine

*myksyd@knu.ua

\begin{abstract}
Significant influence of the quality of educational services in the perception of students is demonstrated by research conducted by scientists at various universities around the world. Such research is the basis of quality assurance policy as part of the strategic management of the university. The quality of educational services is studied by the authors on the basis of the normalized SERVQUAL model. Five partial indices and total index are based on the data collected in eight Ukrainian universities. The high value of the Cronbach"s Alpha coefficient confirmed the internal consistency of the model indicators. Results of ANOVA and comparison of confidence intervals confirmed the differentiating ability of the model: data for different universities differ statistically significantly. The influence of the university ${ }^{\text {ee }}$ ranking place on the general index is revealed.
\end{abstract}

Keywords: HEI, quality of education, SERVQUAL, ranking, university management.

\section{INTRODUCTION}

Ukraine's implementation of Standards and Guidelines for Quality Assurance in European Higher Education Area (ESG) has prompted universities to develop quality assurance policies as part of their strategic management. The policy is implemented in practice through various internal quality assurance processes, including monitoring of various aspects of the educational process. This is explicitly indicated in the paragraph of the Standard about Information Management, which obliges higher education institutions (HEI) to «collect, analyze and use relevant information for the effective management of their programmes and other activities» [1]. Ukrainian universities have begun to work actively to improve the quality of services provided, as fierce competition in the domestic educational market is intensified by an open and high-quality global educational market. On the other hand, high positions of university in any institutional ranking, regardless of the variability of ranking criteria, provide great advantages to the university [2]. The position of the HEI in any ranking is reflected in the number of students, because the prestige of the university has one of the key positions in the list of important factors in choosing an entrant to a higher education institution [3].

\section{METHODOLOGY}

In fact the university policy for quality assurance is the embodiment of the idea of self-organization of universities, which, according to scientists, is «a prerequisite for the creation of autonomous organizations, whose self-realization efficiency is recognized as the most effective in comparison with Weberian bureaucracy and Mintsbergees adhocracy»; their study demonstrates «the efficiency of selforganizing universities and their significance in revealing the nature of man, in particular, the nature of managerial skills» [4]. Under such conditions, the concept of quality, namely the quality of higher education, is key concept in the management of the university. The concept of quality of education has different interpretations; British scientist D. Green successfully summarized them in her book: as "unique" and "excellent" (e.g., in world-renowned institutions); as "the same as expectations and standards" (e.g. ESG); as a target or "for the purpose" (one that satisfies all participants in the educational process - stakeholders); as appropriate to the requirements of consumers and their potential needs [5]. The latter approach actually introduces a new philosophy of higher education. And the sustainable development of HEI requires competition, strategies in which comparative approaches to measuring 
the quality of education in different institutions competing in the education market will provide.

\subsection{Higher Education Service Quality}

In this article, we limit the study of the quality of education to the quality of services, but do not claim that this approach is the only correct and comprehensive. After all, other approaches are no less important and effective and together form no less holistic picture of the subject. For example, university evaluation can better demonstrate the scientific potential of HEI, although «university evaluation should advocate university spirit, guarantee and develop university key function» [6, p. 59]; evaluation of the quality of teaching disciplines - the pedagogical potential of HEI [7], etc.

The opinion of all stakeholders is important for improving the quality of education, or rather - a specific educational program. However, there is some „superstructuree for all educational programs of the university - it is a university environment, the university administration should equally provide it for all its educational programs. Researchers have investigated the significant impact of the quality of services in the perception of students as the main recipients-of-services (stakeholders) directly involved in the university environment on the perception of sustainable development practices of the university, and vice versa $[8 ; 9]$.

The "service" approach to higher education is borrowed from marketing. It originates from a study by American scientists in 1985: A. Parasuraman, V. Zeithaml and L. Berry proposed a conceptual model of service quality:

Satisfaction $(\mathrm{S})=$ Perception $(\mathrm{P})-$ Expectation (E) $[10]$.

«Building on seven years of research on service quality, they construct a model that, by balancing a customer's perceptions of the value of a particular service with the customer's need for that service, provides brilliant theoretical insight into customer expectations and service delivery» [11]. Chinese scientists, analyzing the 5-Gap model of higher education according to A. Parasuraman, V. Zeithaml and L. Berry, note that «learners" satisfaction is the main indicator to service quality evaluation of higher education», so «universities should continue to understand the real needs of students» [12].

Many scientists have been involved in adapting the model of service quality for service quality assessment in the field of higher education $[13 ; 14]$, the authors of the article also [15; 16].

\subsection{Research design}

In this study, a normalized SERVQUAL model was used [14], the adaptation of indicators and measuring ability of which was carried out by the authors $[15 ; 16]$. The general model contains 5 factors: Tangibles (Q1), Reliability (Q2), Responsiveness (Q3), Assurance (Q4), and Empathy (Q5). Indicators and related questions are presented in the article [15]. The measurement scale of each of the 26 indicators is a 7-point Likert scale.

The empirical basis is a data set obtained from a number of educational programs at eight different universities in Ukraine, for confidential purposes, their names are not provided. The survey was conducted on the LimeSurvey platform in 2018; the total sample size is 420 students of different years of study. Data analysis was performed in the SPSS program. Secondary data from the national ranking of universities «Top-200 Ukraine» 2018 and 2019 for universities that participated in the survey were also added to the data set.

The research hypothesis is as follows. All aggregate indices of the SERVQUAL model have differentiating ability, the value of which depends on the university evaluation; the statistical dependence is inverse one.

\section{RESEARCH RESULTS}

One-dimensional distributions of 26 indicators of the SERVQUAL model for each university are also informative, but we will analyze only 5 factors, or indices Q1-Q5, and the total index Q. All indices are cumulative or averaged over their respective indicators.

The high internal consistency of the model is confirmed by the Reliability Analysis. All indicators are correlated; no indicator due to its derivation from the total model or 5 partial models will improve the corresponding Alpha Cronbach's coefficient (Table 1). Due to the splitting of the sample into sub-samples randomly and on the basis of university, or gender, or level of education, the value of the Cronbach's coefficient varied slightly, but all models remained consistent.

Table 1. Reliability Analysis

\begin{tabular}{|c|c|c|c|c|c|c|}
\hline Coeff. & Q & Q1 & Q2 & Q3 & Q4 & Q5 \\
\hline $\begin{array}{c}\text { Cronbach's } \\
\text { Alpha }\end{array}$ & 0,959 & 0,768 & 0,873 & 0,861 & 0,908 & 0,910 \\
\hline
\end{tabular}

The results of the Reliability Analysis made possible to construct indices Q and Q1-Q5, as well as expanded the possibilities of data analysis: at the level of individual indicators of the complete model and the total index Q, as well as at the level of particular models and corresponding indices Q1-Q5. For example, the model Guarantee (Q4) has a partial meaningful correspondence with the model of quality of teaching disciplines [7] or evaluation of course teachers [17].

It is worth noting that all models were also successfully validity with Factor Analysis. The twolevel approach was used by analogy with validization in $[18, \mathrm{p}$. 225]: first 5 one-factor solutions for Q1-Q5, and 
construction of the corresponding averaged indices, then one-factor solution for $\mathrm{Q}$ on the basis of 5 indicesindicators Q1-Q5.

In order to compare the indices Q and Q1-Q5 for different universities, the Mean was used and confidence intervals were constructed for these statistics. Comparison of means by ANOVA revealed statistically significant differences at the level of 0.00 for all indices (see Figure 1 and Figure 2).

Thus, the quality indicator of educational services index $\mathrm{Q}$ - is sensitive to the educational environment (i.e. a particular university), so universities differ in available tangibles: modern equipment in modern buildings, teaching materials and staff, etc. (Q1), reliability of the learning environment: accessibility of faculty"s managers, and awareness of the organization of the educational process and assessment, etc. (Q2), responsiveness, or student-centeredness, etc. (Q3), assurance of the quality of teaching disciplines, etc. (Q4), empathy of teachers and managers of the faculty and university, etc. (Q5). Visualizations (Fig. 1 and Fig. 2) clearly demonstrate that at least the universities selected for analysis differ significantly in the quality of their educational services, so the quality of higher education in these universities cannot be considered the same at the level of acquired competencies. This conclusion can be applied to all universities in Ukraine.

Institutional rankings are indicators of university evaluation. For the case of Ukrainian universities, we used the national rating «Top-200 Ukraine»; as the rating of the current year is formed according to the indicators of the previous year, the data of 2018 and 2019 were selected for analysis. The ranking methodology consists in the construction of 3 separate indices, which are based on the assessment of the quality of scientific and pedagogical potential, the quality of education, and international recognition, respectively; the integrated index of the activity of higher education institutions is the total indicator of all 3 indices, according to which each university is assigned its ordinal place in the general list of universities.

The results of the correlation analysis are presented in Table 2. Since the scales of the analyzed variables are inverted (Q and Q1-Q5 are measured in ascending order, the rating is in descending order), the second part of the hypothesis can be considered confirmed. The better the university"s ranking, the worse the assessments of the quality of educational services provided in it, according to students.

The university ranking reflects the corresponding expectations of students, so the formula Satisfaction $(\mathrm{S})=$ Perception (P) - Expectation (E) [10] is correct for the case of Ukrainian higher education.
Table 2. Correlation Analysis

\begin{tabular}{|c|c|c|c|c|c|c|c|}
\hline Year & Coeff. & Q & Q1 & Q2 & Q3 & Q4 & Q5 \\
\hline \multirow{2}{*}{2018} & C & 0,219 & 0,250 & 0,180 & 0,147 & 0,195 & 0,184 \\
\cline { 2 - 7 } & Sig. & 0,000 & 0,000 & 0,001 & 0,006 & 0,000 & 0,001 \\
\hline \multirow{2}{*}{2019} & C & 0,202 & 0,242 & 0,158 & 0,143 & 0,170 & 0,178 \\
\cline { 2 - 7 } & Sig. & 0,000 & 0,000 & 0,003 & 0,007 & 0,001 & 0,001 \\
\hline
\end{tabular}

\section{DISSCUTION}

Within the framework of the research, there are many issues open for discussion. In particular, some scholars do not support the consumer approach to higher education, so as contrary to autonomy and academic freedom [19; 20]. However, they consider sociological studies of student satisfaction with various aspects of the educational process are the most acceptable in management decisions (e.g., [16]). In fact, university quality assurance policy is based on academic freedom, and autonomous processes in higher education involve variations in such policies.

We can also assume that academic freedom as a key value of university contributes to the openness, sincerity of studentse statements and to some times their dissatisfaction as a desire to make better the subject of discussion - different aspects of educational quality.

And this is reflected in the results gotten according the SERVQUAL model. By analogy, in democratic societies, the level of institutional trust is always lower than in authoritarian regimes, which «can exhibit high levels of political trust» [21, p. 12].

The evaluation of universities by ranking them does not correctly reflect the quality of educational services estimated by students. The university"s rating shapes expectations of the quality of education among entrants, and too high expectations reduce the satisfaction of students in the process of obtaining higher education. It can be assumed that the reputation of the university [22] will more adequately reflect the quality of educational services [23; 24]; however, the authors did not investigate this assumption in this paper.

There are many issues related to the validization of the SERVQUAL model. There is a possibility when within one university the indicators will not be decomposed into 5 factors (models), or will be decomposed in another way. We assume that situational development or selective one in relation to either educational programs, or levels of education, or faculties, or individual resources, etc., of the relevant educational environment may lead to such model inconsistencies. 

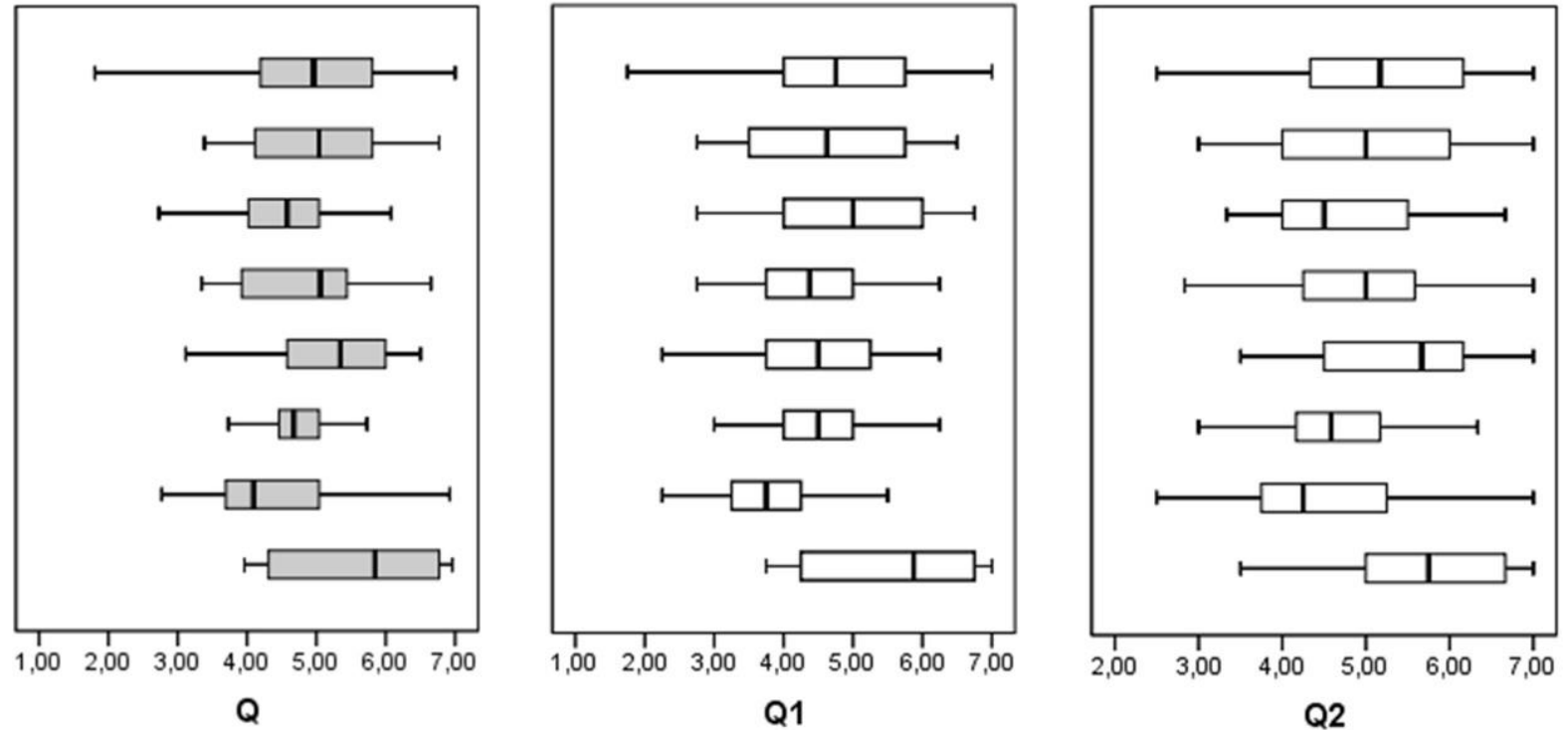

Figure 1 Confidence intervals for total index $\mathbf{Q}$ and partial indices $\mathbf{Q 1}, \mathbf{Q 2}$, aver .

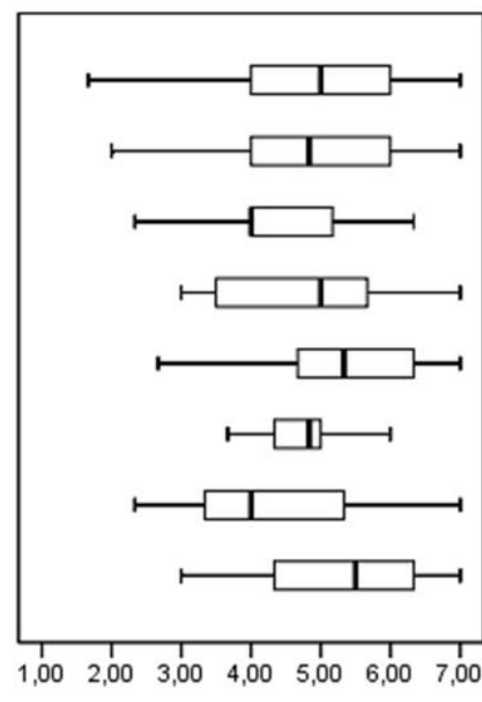

Q3

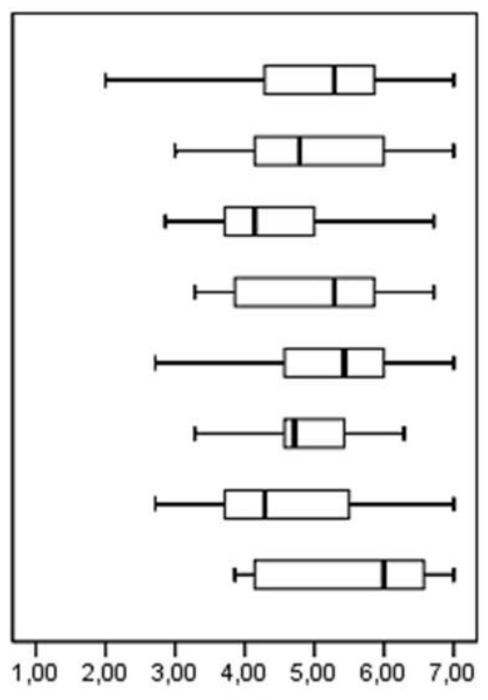

Q4

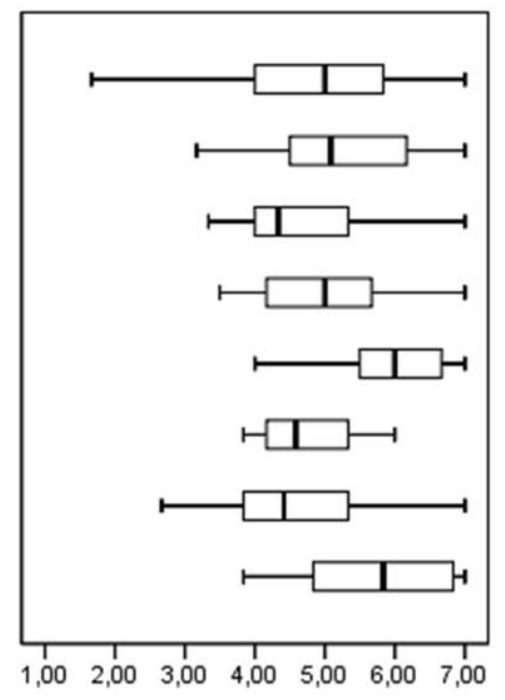

Q5

Figure 2 Confidence intervals for partial indices Q4 and Q5, aver

\section{CONCLUSION}

Higher education in Ukraine is changing at the institutional level and moving towards best European practices. The strategic management of the university includes the policy of quality of education as one of the key policies of successful development. Sustainable development of universities requires competition, the strategy of which will provide comparative approaches to measuring the quality of education in different institutions competing in the educational market.

As part of the approach to the quality of education as appropriate to the requirements of consumers and their potential needs [5], the authors propose a SERVQUAL model, which measures the quality of higher education services in the perception of students, SERVQUAL model is valid and relevant for Ukrainian universities.

Based on the data collected in eight Ukrainian universities among students of all years of study in 2018, five partial indices were constructing: Tangibles (Q1), Reliability (Q2), Responsiveness (Q3), Assurance (Q4), and Empathy (Q5), and one total index Q.

Results of ANOVA and comparison of confidence intervals confirmed the differentiating ability of the model: data for different universities differ statistically significantly. Therefore, the SERVQUAL model is 
sensitive to the peculiarities of the educational environment.

Adding to the array of data the secondary data of the national ranking in 2018 and 2019 confirmed the hypothesis that the indicators of the model depend on the ranking of the university in the «Top 200 Ukraine». The authors believe that this is due to the high expectations of students for the quality of services, which are formed under the influence of the ranking and the level of academic freedom at the university too. The first assumption is a confirmation of the formula Satisfaction $(\mathrm{S})=$ Perception $(\mathrm{P})-$ Expectation (E) [10], but encourages the search for another indicator of university evaluation, such as the reputation of the university. The second assumption requires additional research or techniques.

Although the educational environment may cause the changes in the structure of the SERVQUAL model, this model is suitable for a comparative study of the quality of educational services in different universities.

\section{AUTHORS’ CONTRIBUTIONS}

M. Sydorov is the head of university projects related to the internal quality assurance of education, as well as projects to study the quality of education in Ukraine. His competence is the formation of an array of data (from data collection on the LimeSurvey platform to the input of secondary data), selection and testing of the model (pretest, focus group discussions), the idea of visual comparison of all indices $\mathrm{Q}$.

S. Salnikova proposed the logic of presenting this study, the idea of considering the evaluation of universities as an indicator of expectations, and applying a two-level factor model for validization of the SERVQUAL model; she also did a data analysis.

\section{ACKNOWLEDGMENTS}

The authors thank the universities that participated in the survey on a voluntary basis, and colleagues who participated at different stages of the sociological study.

\section{REFERENCES}

[1] Standards and Guidelines for Quality Assurance in the European Higher Education Area (ESG) (2015), Brussels, Belgium, 32 p., available at: https://enqa.eu/index.php/home/esg/

[2] P. Sreeramana Aithal and P.M. Suresh Kumar (2016), "ABC Model of Research Productivity and Higher Educational Institutional Ranking", International Journal of Education and Management Engineering, Vol. 6, No. 6, pp. 74-84. DOI: $10.5815 /$ ijeme.2016.06.08

[3] Kavtseniuk, M. (2017), "The selection of entrants in 2016: quantity and quality", CEDOS, available at: $\quad$ https://cedos.org.ua/en/articles/vybirabituriientiv-2016-roku-kilkist-ta-iakist

[4] Bilohur, V. Kravchenko, O. LishchukTorchynska, T. and Yukhymenko, N. (2020), "Generic and professional managerial skills: changing nature, thinking and roles", Naukovyi Visnyk Natsionalnoho Hirnychoho Universytetu, No. 3, pp. 151-156. DOI: doi.org/10.33271/nvngu/2020$3 / 151$

[5] D. Green and ed. (1994), What is Quality in Higher Education, SRHE \& Open University Press, 132 p.

[6] Qi-Ming, W. Xi-nan, Zhao and Li-li, Zh. (2013), “A Novel Thought and Method of University Evaluation", International Journal of Education and Management Engineering, Vol. 3, No. 2, pp. 59-65. DOI: 10.5815/ijeme.2013.02.10

[7] Salnikova, S. and Lishchuk-Torchynska, T. (2008), "Methodical Particularities of Organization and Conducting of the General University Sociological Research "Teacher through the Eyes of Students", Bulletin of V.N. Karazin Kharkiv National University: Sociological study of contemporary society: methodology, theory, methods, No. 800, pp. 172- 177 .

[8] Chaudhary, S. and Dey, A.K. (2020), "Influence of studentperceived service quality on sustainability practices of university and student satisfaction", Quality Assurance in Education, Vol. 28, No. 4, available at: https://doi.org/10.1108/QAE-10-20190107

[9] Olmos-Gómez, M.D.C. Suárez, M.L. Ferrara, C. and Olmedo-Moreno, E.M. (2020), "Quality of higher education through the pursuit of satisfaction with a focus on sustainability", Sustainability, vol 12(6), pp. 23-66.

[10] Parasuraman, A. Zeithaml, V.A. and Berry, L.L. (1985), “A Conceptual Model of Service Quality and Its Implications for Future Research", The Journal of Marketing, vol. 49(4), pp. 41-50. DOI: 10.1177/002224298504900403

[11] Zeithaml, V.A. Parasuraman, A. and Berry, L.L. (1990), "Delivering Quality Service: Balancing Customer Perceptions and Expectations", Free Press, Collier Macmillan, New York, London.

[12] Zhiqin, L. and Jianguo, F. Fang, W. and Xin, D. (2012), "Study on Higher Education Service Quality Based on Student Perception", International Journal of Education and Management Engineering, Vol. 2, No. 4, pp. 22-27. DOI: 10.5815/ijeme.2012.04.04

[13] Tan, K.C. and Kek, S.W. (2004), "Service Quality in Higher Education Using an Enhanced SERVQUAL Approach", Quality in Higher Education, vol. $10(1)$, pp. 17-24. DOI: doi.org/10.1080/1353832242000195032 
[14] Đonlagić, S. and Fazlić, S. (2015), "Quality assessment in higher education using the SERVQUAL model", Management, Vol. 20, No. 1, pp. 39-57.

[15] Sydorov, M. Salnikova, S. Savelyev, Yu. Oliinyk, O. (2020), "Modified SERVPERF and Normalized SERVQUAL Models in Estimation of Service Quality in Higher Educational Institutes", Sociological Studios, No. 1 (16), pp. 29-39. DOI: doi.org/10.29038/2306-3971-2020-01-29-39

[16] Sydorov, M. Dovbnya, V. (2019), "Factors of Students Satisfaction of the Educational Process (on the example of the study of Taras Shevchenko National University students)", Sociological Studios, No. 1(14), pp. 42-52. DOI: doi.org/10.29038/2306-3971-2019-01-45-52

[17] Mahfida Amjad and Nusrat Jahan Linda, (2020), “A Web Based Automated Tool for Course Teacher Evaluation System (TTE)", International Journal of Education and Management Engineering, Vol. 10, No. 2, pp. 11-19. DOI: 10.5815/ijeme.2020.02.02

[18] Salnikova, S. (2010), "Multidimensional modelling as analytical strategy of religiosity measurement", Methodology, the theory and practice of sociological analysis of modern society, Issue 16, pp. 222-229.

[19] Harvey, L. and James, W. (2010), "Fifteen Years of Quality in Higher Education (Part two)", Qual. High. Educ., Vol. 16, No. 2, pp. 81-113. DOI: https://doi.org/10.1080/13538322.2010.485722

[20] Enders, J. and Westerheijden, D.F. (2014), "Quality Assurance in the European Policy Arena", Policy and Society, Vol. 33, No. 3, pp. 167-176. DOI: doi.org/10.1016/j.polsoc.2014.09.004

[21] Vallier, K. (2019), "Social and Political Trust: concepts, causes and consequences", Niskanen Center, Washington, $16 \mathrm{p}$.

[22] Strathdee, R. (2009), "Reputation in the sociology of education", British Journal of Sociology of Education, Vol. 30, No. 1, pp. 83-96. DOI: $10.1080 / 01425690802514482$

[23] Susila Munisamy, Noor Ismawati Mohd Jaafar, and Shyamala Nagaraj (2014), Does Reputation Matter? Case Study of Undergraduate Choice at a Premier University, Asia-Pacific Education Researcher, Vol. 23, No. 3, pp. 451-462. DOI: 10.1007/s40299013-0120-y

[24] Brewer, A. and Zhao, J. (2010) “The impact of a pathway college on reputation and brand awareness for its affiliated university in Sydney", International Journal of Educational Management, Vol. 24, No. 1, pp. 34-47. DOI: $10.1108 / 09513541011013033$ 